\title{
EL PARTIT DELS SOCIALISTES DE CATALUNYA
}

\author{
Gabriel Colomé \\ (Universitat Autònoma de Barcelona)
}

\section{UNIFICACIO I CONSTRUCCIO DEL PARTIT}

El Partit dels Socialistes de Catalunya fou creat el juliol del 1978 per la unificacio de tres partits existents, que es dissolgueren per formar-lo: PSC-Congrés, PSC-Reagrupament i la Federació Catalana deI PSOE.

La fusió dels tres partits es realitzà en dos temps. El dia 15 de juliol de 1978 foren convocats els congressos tespectius per acceptat la dissolució dels antics partits i la integració en el nou, i cadascun aprovà el Protocol d'Unitat. El dia següent, 16 de juliol, se celebrà el Congrés d'unificació. La representació dels delegats congressuals es féu a partir de les dades d'afiliats de cada partit. PSC-C i FC del PSOE obtingueren la mateixa quota congressual, 450 delegats cadascun, mentre que la del PSC-R fou molt baixa, només 100 delegats. A més, es tepartí d'igual manera la quota de representació en la futura Executiva del nou partit, amb el resul. tat d'1 1 membres per al PSC-C, 11 per a la FC del PSOE i 3 per al PSC-R.

Fou en el Congrés de la FC del PSOE on es produí el fet més rellevant, quan no fou aprovada la gestió de l'Executiva, encap̧̧alada per Josep M. Triginer, contra la qual votaren el 46 per cent dels delegats per tan sols un 26 per cent a favor. Es podia llegir en el Diario de Barcelona que «esta desautorización parece una maniobra destinada a socavar la posicion de Triginer, cuya postura ba quedado muy debilitada. En concreto, miembros de la base del partido afirmaban su decisión de desplazar a Tri- 
giner acusándole poco menos que de liquidacionistan. ${ }^{1}$ Aquesta crítica estava fonamentada en el fet que un sector de la Federació pensava que eren els altres dos partits els qui s'integraven en la FC del PSOE i no que comportés la dissolució d'aquesta. Aquesta desautorització provocà la caiguda posterior de Triginer de la Sectetaria d'Organització en la nova Executiva del partit fusionat, i la seva plaça fou ocupada per un destacat ugetista, Carlos Cigarrán, que es convertí, de fet, en el númeto dos del nou Partit Socialista.

La Federació Catalana del PSOE renuncià a la voluntat expressa que qualsevol procés d'unitat es realitzés sota la condició d'estructurar el nou partit com una Federació del PSOE. Aixi, el PSC (PSC-PSOE) es definí com un partit sobirà, i com a tal decidia de participar en organismes representatius comuns amb el PSOE. Encara que la FC del PSOE políticament sortia enfortida, com ho declarà Joaquim Jou, membre del Comitè Federal del PSOE, quan afirmà que «nosotros bemos becbo concesiones léxicas, tales como admitir el término "soberania". Pero cabe preguntarse a qué equivale ese término si luego se admite que coticemos a nivel estatal $i$ que exista una misma disciplina parlamentaria en el seno del PSOE».2

El Congrés del PSC-C tingué també els seus moments tensos protagonitzats per la tendència més catalanista del partit, anomenada II Congrés, que oferí una forta resistència presentant esmenes als Estatuts del nou partit. Però l'acceptació total de la fusió pex part dels dirigents del partit fou decisiva per deixar en minoria aquesta tendència. El PSC-R celebrà el seu Congtés sense entrebancs, i la seva representació en el Congrés d'Unificació fou minoritària. Dels tres partits fundadors, el Reagrupament fou qui perdé una major part d'afiliats, que es negaren a entrar en el procés de fusió.

Però, ¿quin era el pensament del màxim dirigent del PSOE sobre l'articulació del socialisme en l'àmbit estatal i sobre quines bases s'havia d'estructurar la unitat socialista? La unitat del socialisme, per a Felipe González, es planteja sobre dues tesis diferents, unna que pretende articular al socialismo en el seno de un partido federal y otra que parte de la configuración de múltiples partidos de regionalidad y nacionalidad que se federan entre sim. ${ }^{3}$ La millor estructuració del socialisme unificat, per a Gon-

1. Diario de Barcelona, diumenge 16 de juliol, 1978, p. 17.

2. El Pais, dimarts 18 de juliol, 1978, p. 15.

3. González, F., Socialismo es libertad, Barcelona, Galba, 1978, p. 198. Aquestes dues visions diferenciades de la unitat del socialisme comporten per al líder del PSOE que, en primer lloc, «un partido debe tener una concepción clara de cómo ba de articularse el Estado y de qué ámbitos autonómicos deben tener las diferentes nacionalidades 
zález, és la federal, en la qual estructuració s'esglaonaria de la següent manera: un Congrés unitari que defineix les grans línies estratègiques del partit. ${ }^{4}$ Congrés que escull la direcció del partit, tant a nivell executiu com permanent (Comitè Federal) $i$, finalment, «en las autonomias y regionalidades se estructuraria la organización de forma autonómica. Celebrarian sus congresos para adaptar la linea global establecida a las circunstancias especificas de su nacionalidad o regionalidad, para configurar sus propios estatutos de funcionamiento, designar los organismos rectores de su vida politica y responder a los problemas especiticos de la nacionalidad o regionalidadn. ${ }^{5}$

En els tres Protocols d'Unitat de cadascun dels tres partits es cotnprova les diferències existents entre ells a l'hora de la unificació, i si la idea general exposada per Felipe González es trasllueix en els documents de la unitat del socialisme català.

En primer lloc, el tema de la sobirania del partit en el Protocol d'Unitat és definida en el quatt punt: «El Partit dels Socialistes de Catalunya (PSC.PSOE) tindrà plena sobirania en aquells àmbits de competències que els socialistes de Catalunya propugnem per l'organització política del rostre país, d'acord amb el marc constitucional aprovat en el setz programa pels socialistes de tot l'Estat.» EI Protocol final teserva la plena sobirania del partit només en aquells àmbits de Catalunya, d'acord amb el progra. ma dels socialistes de tot l'Estat, és a dir el PSOE.

En segon lloc, les relacions que s'estableixen amb el PSOE. La Federacio Catalana estructurava les relacions amb el PSOE en el matc, no tant d'un partit federat, sinó com una Federació més. El PSC-C, per la seva part, entenia que "el PSC sorgit de la unificació, en virtut de la seva sobirania, configurarà la seva articulació amb el PSOE, en la perspectiva de la unitat de tots els socialistes de l'Estat»."

El tercer punt és el referent a la qüestió sindical, tema que només és plasmat en el document de la Federació, i no és esmentat pels altres dos partits.

L'origen històric dels tres partits els diferenciava en llur concepció del que havia d'ésser el moviment sindical. Els tres defensaven la unitat sindical en una sola central en què hi hagués representades les diverses

y regionalidades en el seno de una concepción federal». En segon $H_{0} \times$, «Nos parece errónea la tesis de la articulación del socialismo a partir de la existencia de grupos o partidos socialistas independientes que se relacionan entre sí por la cúspide, por la di. reccion representativa de estos grupos».

4. González, F., op. cit., 1976, p. 63.

5. González, F., op. cit., 1978, p. 200.

6. Document final del Protocol d'Unitat, 16 de juliol de 1978. 
tendències del moviment obter. El punt de conflicte que els dividia era la forma de realitzar-la.

La Federació Catalana del PSOE pretenia que la unitat sindical es realitzés entorn al sindicat socialista UGT i pensava que l'únic camí per aconseguir-ho era la potenciació d'aquest sindicat. Per la seva banda, el PSC-C, influit per la diversitat d'opcions sindicals de Catalunya, tenia els seus afiliats dispersos en diferents centrals sindicals. Defensava la unitat sindical però no imposava als seus affliats la militància en cap sindicat en concret. De l'obligatorietat que pretenia la $\mathrm{FC}$ del $\mathrm{PSOE}$ es passà a deixar la porta oberta, i la referència a la UGT quedà només com una opció sindical.

No serà fins al III Congrés del 1982 quan s'introduirà la modificació de l'obligatorietat de militar sindicalment en la UGT. Aquest canvi de postura va ésser possible per l'apropament entre el partit i el sindicat $i$, en gran mesura, per haver deixat d'ésser el reducte del sector perdedor del II Congrés.

Es pot afirmar, a la vista del document final tesultant, que la FC del PSOE fou qui sortí més beneficiada en veure recollides moltes de les pron postes del seu document, a més d'eliminar-se totes les referències d'una plena i total sobirania del nou partit respecte del PSOE. De les dues tesis exposades anteriorment per Felipe González, la primera és la que és recollida pels socialistes catalans en el document final d'unitat.

La forma d'organització $i$ de treball de cadascun dels partits originà grans problemes un cop aconseguida la unitat dels tres collectius. La FC del PSOE era un partit molt jerarquitzat i rígid en comparació amb el PSC.C. La FC prohibia explícitament les tendències organitzades ja que el PSOE era un partit molt definit tant en la seva estructura com en la seva organització. El PSC-C, en canvi, era fruit de la unificació de díferents partits i grups de l'esquerra catalana i legitimava l'existència i actuació de tendències organitzades dins del partit. Els socialistes del PSC-C varen construit una organització molt flexible i poc jetarquitzada. EI PSC-R s'assemblava més, en aquest aspecte, al PSC-C que a la Federació. Reconeixia el funcionament de les tendències petò prohibia llur organització. En el Congtés d'Unitat s'arribà a una solució de compromís entre les diferències marcades pels tres partits. La solució que es va adoptar fou ambigua, tal com ho recullen els Estatuts del nou partit: «La llibertat de discussió i d'expressió serà absoluta en tots els nivells del partit. Els diferents cor. tents d'opinió podran expressar-se dins del partit. No podrà constituir-se cap tendència organitzada dins del partit» (Art. 2b).

El 16 de juliol de 1978, el Congrés constituent del Partit Socialista elegia la nova Executiva, encapçalada per Joan Reventós. Aquesta elecció tancava un llarg procés per poder unificar en un sol partit els socialistes 
de Catalunya. Amb la unificació, però, no es tancava la porta als conflictes que s'originarien en el si del nou partit entre les dues tendències representatives de dues concepcions diferents de socialisme. Concepcions que provenen d'una tradició històrica diferenciada.

Aquestes dues tradicions $\mathrm{i}$ concepcions socialistes diferenciades poden descriure's de la següent manera: la tradició socialista provinent del PSC-C. pren les seves arrels històriques en el moviment cooperativista, en l'anarco-sindicalisme, en el catalanisme, és anticentralista, antiestatista i autogestionària, $i$ amb fortes influències del cristianisme de caire social. En canvi, el PSOE representaria el socialistne de tradició republicana, laica, obrerista, centralista i estatista. Dins del marc general del socialisme, la tradició socialista del PSOE se situa dins del corrent «estatal»; en canvi, la tradició socialista del PSC-C es trobaria emmarcada dins del corrent «societal».

Un dels temes de diferenciació cal situar-lo en l'autogestió, que setà reflexionat intellectualment pel Front Obrer de Catalunya i, en canvi, segons Reventós, «en el MSC serà més una qüestió subconscient que racional»? El tema de l'autogestió és recollit a França pel PSU de Rocard, que el reformula expurgant-lo de les seves connotacions iugoslaves. Pels socialistes catalans aquestes formulacions provinents de França seran les que els impregnaran.

Cadascuna de les dues tradicions representa el que Michel Rocard anomenà «les dues cultures» en el discurs que va fer, el 1977, en el Congrés de Nantes del Parti Socialiste: «L'une est jacobine, centralisatrice, étatique, nationaliste et protectioniste. Elle procède d'une lecture caricaturale et sclérosée d'un marxisme travesti. L'autre culture est descentralisatrice, régionaliste. Elle refuse les dominations arbitraires. Elle se méfie du règle. ment et de l'administration, elle préfère l'autonomie aux collectivités de base et l'experimentation."

La diferència bàsica entre uns $i$ altres repercutirà en les contradiccions inherents que aquest fet comportarà en el si del partit unificat. Dues concepcions antagòniques $\mathrm{i}$ dues tradicions que volen obtenir la preeminència interna. ${ }^{8}$

7. Entrevista personal realizzada a Joan Reventós (Patis, 10 de febrex de 1986): «E\} sediment històric del Partit Socialista cal cercar-lo en primer lloc, en el cooperativisme, en segon, en l'anarco-sindicalisme i l'experiència de la guerra, en tercer, en l'impacte del model iugosiau que aporta l'estructura de l'Estat i el tema de l'autogestió, i fnalment, en els cristians pel socialisme amb una gran influència escolar cristiana en eis futurs dirigents.»

8. De Esteban, I.; López Guerra, L., op cit., p. 119: «Una situación similar se produjo en Cataluña, donde los núcleos procedentes del PSC mantwvieron, después de su integración en el nuevo PSC-PSOE, no sólo sus diferencias internas, sino una aguda $n$ - 
El màxim grau d'antagonisme es produí en el II Congrés del Partit Socialista, el 1980. Arribava el partit al seu primer Congrés com a partit unificat després d'haver guanyat a Catalunya les eleccions generals de 1979 i les municipals d'aquell mateix any, després de la signatura del «Pacte de Progrés», però la derrota en les eleccions al Parlament de Catalunya, un cop aprovat l'Estatut d'autonomia, quan les expectatives dels socialistes eren molt grans, va posar el partit en una profunda depressió. A més; el PSC refusà l'oferta realitzada per Jordi Pujol la mateixa nit electoral, $i$ repetida en el debat d'investidura, d'entrar a formar part del Govern de Ia Generalitat."

La derrota electoral del 20 de març de 1980 havia estat precedida pels conflictes en la confecció de les llistes electorals entre els òrgans executius del partit i el sindicat socialista Unió General de Treballadors (UGT). Aquest fet, afegit a la frustració per la derrota a mans de la coalició Convergència $i$ Unió, liderada per Jordi Pujol, i la dimissió anterior de Raimon Obiols de l'Executiva el 1979 -en desacord pel manteniment de les quotes de representació pactades en la fusió per a cada partit, cosa que el portà a presentar-se al Congrés encapçalant el cortent aromenat «unitarista», que propugnava trencar amb les quotes existents de representació per als tres partits fundadors $i$ realitzar realment la unitat- varen ésser els detonants de la crisi que s'obrí en el si del partit i que fou dirimida en el transcurs del II Congrés. Les conseqüències de la crisi foren, per una banda, salvar el jove partit de la ruptura; per una altra, la sortida dels antics membres de la Federació Catalana del PSOE del si de l'òrgan executiu del partit, retirada que comportà el trencament de l'equilibri inestable aconseguit en el moment de la fundació, i el decantament cap a una de les dues parts.

En aquest sentit afirma Jaume Lorés que «cal fer ressaltar, com a exemple clarificador d'aquesta fragilitat socialista, que la primera resposta del PSC a la victòria de Pujol fou, altra vegada, una greu crisi en el seu Congrés, immediat efecte dels enfrontaments entre el sector anomenat "nacionalista" i personalment fidel a Joan Reventós, encapçalat per Raimon

validad con los grupos procedentes de la anterior Federación Catalana del PSOE, y con los directivos de la Union General de Trabajadores en Cataluña.»

9. Entrevista personal tealitzada a Raimon Obiols els dies 26 d'octubre i 6 de no. vembre de 1987: «E1 dubte era si l'oferta de Pujol era real o només una figura retorica. En tot cas, la majoria total del Partit hi estava en contra. Crec que vam cometre dos efrors, el primer no haver intentat l'apropament a altres forces de progrés, ERC i PSUC. EI segon exa pensat que la situació a Catalunya estava normalitzada i, per tant, per. metia un joc Majoria-Minoria / Govern-Oposició.» 
Obiols, i els sectors impregnats per les tesis del PSOE, donant un signe clar de com el PSC havia aconseguit la unitat socialista a Catalunya». ${ }^{10}$

El Pattit Socialista va estar a punt de trencar-se però s'evità la ruptura perquè el PSOE declarà que només reconeixeria allò que sortís del Congrés. Com ja s'ha dit, la Comissió Executiva del partit, encapçalada per Joan Reventós, no va poder teconstruir la unitat perduda ja gue el sector «obrerista» es negà a formar-ne part. Raimon Obiols va ésser l'encarregat de la tasca d'estructuració i organització del Partit Socialista des del seu càrrec en l'Executiva. Però el fet important que s'ha de destacar és que es trencava, a partir d'aquell moment, amb la representació dels partits fundadors a través de quotes. La fràgil unitat s'aconseguí mantenir a través del respecte pels perdedors d'aquest Congrés i amb una política de gestos cap a aquest sector. «En Cataluña, las continuas tensiones entre antiguos miembros de la tederación catalana del PSOE y ex-dirigentes del PSC reflejaba en un microcosmos las tensiones básicas entre catalanes de nacimiento y la comunidad inmigrante. La estructura federal del partido sólo en parte babía logrado favorecer la regulación de estos conflictos centro-periferia: por un lado, la existencia de organizaciones regionales autónomas o semiautónomas ayudó a impedir que los conflictos regionales diesen al traste con las funciones básicas de los órganos centrales del partido; mientras la Comisión Ejecutiva Federal evitara mezclarse en las disputas entre nacionalistas catalanes e inmigrantes, por ejemplo, no existiría ningún obstáculo intrinseco para una cooperación continua y estrecba entre los antiguos miembros del PSC que dominaban la dirección de esa organización regional y los dirigentes del PSOE en Madrid.»"1

La segona crisi interna del partit, després de l'intent de cop d'Estat del febrer de 1981, fou motivada pel pacte entre Ia UCD i el PSOE sobre la qüestió autonòmica i la subsegüent aprovació de la Llei Orgànica d'Harmonització del Procés Autonòmic, la famosa «LOHPA». El fet més destacable que provocà la crisi fou la no-presentació de les esmenes redactades a la llei, per part del portaveu Ernest Lluch, el qual va ésser cessat

10. Lorés, J., La transició a Catalunya (1977-1984), Barcelona, Empúries, 1985, p. 76: «L'espectacle que donaren els anomenats "baxons" o "institucionals" del PSC en aquell Congrés dividit no prenent cap actitud definida, deixant en Joan Reventós aillat i sol, pel fet d'estar massa pendent de les repercussions d'aquella crisi als ulls de la decisòria executiva espanyola, va fer néixer la forta sospita que el PSC estava sotmès a un doble poder, amb interessos polítics i personals diversos: el de l'Executiva, encapçalat per Reventós i Obiols, fent-li costat els militants nacionalistes, i els diversos "poders institucionals" en Ajuntaments i Diputacions, que actuaven gairebé per sobte el partit amb el suport dels quadres mitjans d'aquest, que tenien càrtecs temunerats i de confiança en els poders locals,»

11. Gunther, R.; Sani, G.; Shabad, G., op. cit., p. 187.

6. 
d'aquest càrrec. Dos membres de la Comissió Executiva varen dimitir per aquest motiu, Eduardo Martín Toval i Joan Prats i Català. De nou, l'equilibri inestable havia estat trencat i aquesta vegada, com l'anterior, en el mateix sentit.

La victòria a les eleccions generals del 28 d'octubre de 1982 i la pujada del PSOE al govern de l'Estat varen reconduir la recomposició, en part, de l'equilibri intern $i$, en gran mesura, de la unitat del partit perduda en el II Congrés, fet aconseguit, poc abans de les eleccions, en el III Congrés del partit. El Congrés de 1982, celebrat a Castelldefels, fou la confirmació del sector que havia pres el poder dos anys abans en vèncer el sector anomenat Nueva Mayoria, compost per Martín Toval, Lluch, Fàbregas, Triginer i Prats.

La corresponsabilitat en les tasques de govern amb dos ministres del PSC, Narcís Serra i Ernest Lluch en ei Govern del 1982, per una banda, i les victòties electorals a les generals del $1986 \mathrm{i}$ a les municipals del 1983 i 1987, per l'altra, varen ajudar a la consolidació i estabilització del partit. Partit que tornà, en 1984 i 1988, a perdre les eleccions autonòmiques, però aquestes dertotes electorals ja no varen produir cap tipus de crisi interna. Raimon Obiois fou nomenat primer secretari en el Congrés Extraordinari del 1983 en substitució de Joan Reventós, designat ambaixador a França, i s'inicià la fase de consolidació del partit.

\section{ESTRUCTURA INTERNA: REGULACIO ESTATUTARIA}

En l'anàlisi dels Estatuts del Partit Socialista es pot comprovar que aquest s'estructura com un partit de masses, tal i com el va analitzar l'estudiós francès Maurice Duverget. ${ }^{12}$ Es un partit de masses de classe ja que "proposa com a objectius la consecució d'una societat sense classes, socialista $i$ autogestionària en la qual desaparegui qualsevol signe d'explotació i opressió de classe o nacional i la reivindicació de la personalitat nacional de Catalunya» (Art. 2). És un partit, per tant, que es defineix de classe $\mathrm{i}$ nacional. Cal remarcar que la referència a l'autogestió ens indica on se situa el Partit Socialista dins de la tradició del socialisme. En segon lloc, és un partit d'afliacio directa (Art. 6), característica dels partits socialistes europeus continentals, contraposat a un model d'afiliació indirecta, l'exemple més significatiu del qual serien els partits de tradició laborista.

L'estructura isterna del partit té tres nivells que anomenaré de la ma-

12. Duverger, M., Los partidos políticos, México, FCE, 1981. 
nera següent: Local, Federació i Nacional. Cada nivell representa «components de l'organisme del partit (...) no és més que una part d'un tot, l'existència separada de la qual no és concebiblem..$^{13}$

El primer nivell és el Local, que es compon de l'Agrupació, que «és l'organització d'enquadrament polític, tesponsable en el seu àmbit de la política global del Partit» (Art. 14). I s'afegeix que «les Agrupacions es constituiran en base a criteris geogràfics $i$ administratius, de manera que cada Agrupació comprengui un municipi o bé teuneixi diversos municipis en una Agrupació» (Art. 14).

Existeixen quatre tipus diferents d'Agrupació: de barri, municipi i comarca i la sectorial, que és una excepció al criteri geogràfic. L'Agrupació municipal és la més generalitzada en el partit.

Els afiliats d'Agrupacions poden pertànyer a l'organització sectorial del partit, que comprèn els Fronts d'Acció $i$ les Comissions d'Acció Sectorial, creats pel Consell Nacional a proposta de la Comissió Executiva del Pertit (Art. 26). En 1'Organització Sectorial «s'integren els militants que s'agrupen en funció d'un àmbit especialitzat d'activitat política» (Art. 15).

L'estructura interna de l'Agrupació es compon d'una Assemblea, òrgan màxim de decisió (Art. 23), que elegeix la Comissió Executiva que executa les resolucions de l'Assemblea (Art. 24). L'Agrupació representa en l'estructura interna general del partit la base que el sustenta $\mathfrak{i}$, com afirma Duverger, «tracta de cercar membres, multiplicar el seu nombre, engruixir els seus efectius. La quantitat l'importa abans que tot»..4

El segon nivell és el de Federació, que «coordina les organitzacions del Partit en el seu àmbit» (Art. 12). La Federació està constituida per totes les Agrupacions ubicades en el seu territori (Art. 18). I s'afegeix més endavant que «cada Federació integrarà una part $o$ un conjunt de comarques d'acord amb els criteris de proximitat geogràfica, nombre d'afiliats i les característiques sòcio-econòmiques» (Art. 12). EI Congrés del Partit fixa el nombre d'afiliats i la seva composició i el Consell Nacional del Partit pot modificar-ho de manera provisional amb l'acord de la Federació afectada.

En aquest nivell es poden diferenciar quatre tipus de Federació: la mutnicipal, la comarcal, la pluricomarcal i comatques seccionades. La distribució dels diferents tipus de Federacions manté un cert equilibri entre comarcals i pluricomarcals, mentre que les altres dues són minoritàries. ${ }^{15}$

13. Duverger, M., op. cit., p. 47.

14. Duverger, M., op. cit., p. 53.

15. Cal fer esment de la comarca del Barcelonès, seccionada en dues federacions municipals (Barcelona i l'Hospitalet) i una altra que comptèn la resta de la comarca; del Vallès Occidental, dividit en dues federacions, una municipal (Sabadell) i l'altra que 
L'estructura interna de la Federació està integrada per «l'Assemblea, que és l'òrgan màxim del Partit en el seu àmbit. Estarà formada per la totalitat de militants o bé per representants de les Agrupacions en proporció al nombre de militants» (Art. 19). El Consell, que és l'òrgan màxim de direcció, ${ }^{16}$ el qual està compost, a grans trets, pels membres de la Comissió Executiva de la Federació i, per una banda, els membres elegits per l'Assemblea de la Federació i, per l'altra, els membres elegits per les Assemblees de les Agrupacions (Art. 20). I, finalment, la Comissió Executiva, que executa els acords de l'Assemblea $i$ les decisions del Consell (Art. 21). Els membres de l'Executiva són elegits per l'Assemblea.

La Federació se situaria en el nivell intermedi de l'estructura general del partit, en el nivell de coordinació entre la base $\mathrm{i}$ les instàncies superiors de direcció. Aquests dos nivells, el local i el federal, afavoreixen «una jerarquia més clara i la separació de funcions més precisa»..$^{17}$ Però també, i alhora, comporten una complexitat en l'organització interna.

La composició dels dos nivells amb la participació dels membres i l'elecció dels seus òrgans de direcció correspon, segons Duverger, «almenys de manera teòrica, a les exigències de la democràcia política». ${ }^{18}$

Un cop vistes les estructures bàsiques del partit, cal qüestionar-se com aquestes, Federació i Agrupació, han evolucionat i s'han implementat en el teixit de Catalunya. El creixement en nombre de Federacions és de 4, havent passat de 20 (1979) a 24 (1984). El creixement de les Agrupacions ha estat constant en tot el pexíode analitzat, havent passat de 136 (1979) a 277 (1985), amb un petit decreixement a partir de 1983 (278) i 1984 (281). En tot cas, el Partit Socialista, un cop posada en marxa la unificació, ha creat 141 noves Agrupacions. Això demostra que existeix una implantació $i$ un creixement en l'evolució, però també que hi ha man. cances, ja que el partit manté unes zones de nulla o escassa penetració $i$, al contrari, altres de forta concentració.

Es pot afrmar, observant el nucli bàsic de més implantació organitzativa, les zones on aquesta és rellevant $i$ les zones on la implantació és molt feble, que el Partit Socialista es caracteritza per una estructura organitzativa que se situa de manera predominant en les zones urbanes $i$ industrials, on existeix un grau elevat d'immigtació. De la mateixa maneta, el Partit Socialista no aconsegueix implantar-se en les zones rurals, sobre-

agrupa la resta de la comarca; i a la fi, de la comarca del Baix Llobregat, que està dívidida en dues federacions que comprenen el sud $i$ el nord de la comarca.

16. Composició del Consell de Federació (Art. 20 dels Estatuts de 1984).

17. Duverger, M., op. cit, p. 54 .

18. Duverget, M., op. cit., p. 55 . 
tot les més deprimides econòmicament $\mathrm{i}$ on existeix una taxa baixa d'immigració.

El tercer nivell és el Nacional, que es compon dels òrgans de ditecció i de control del partit. Els òrgans de direcció estan constituits pel Congrés, el Consell Nacional i la Comissió Executiva del Partit. Els òrgans de control són la Comissió Nacional de Conflictes i la Comissió General de Control Financer. ${ }^{19}$

El Congrés del Partit és «l'òrgan suprem del Partit, tindtà competència exclusiva per establit la seva estructura interna, regular la seva disciplina i elaborar la seva política i el seu programa» (Art. 28). Les Agrupacions són qui forneixen els delegats congressuals en proporció al nombre d'afiliats de cadascuna.

En la tradició dels partits socialistes com el Labour Party o el PSOE, el primer dia de Congrés, la Comissió Executiva sortint posa la seva gestió a la crítica de les delegacions, només es poden formular crítiques i només els membres que componen l'Executiva poden defensar llur gestió. El Congrés elegeix una nova Comissió Executiva, els representants del partit al Comitè Federal del PSOE, les Comissions de Control Financer i de Conflictes, $i$ una part del Consell Nacional.

El Consell Nacional és «l'òrgan màxim de direcció política del Partit entre Congrés i Congrés» (Art. 34); la seva composició ha anat variant al llarg dels anys, però el que cal remarcar és que és un òrgan massa nombrós per ésser operatiu. El Conseli Nacional és el centre de resolució política, no l'òrgan de debat polític. Hi ha tres categories de membres deI Consell Nacional: els consellers ${ }^{20}$ els membres de la Comissió Executiva i els representants del partit al Comitè Federal del PSOE.

La Comissió Executiva «executa els acords del Congrés i les decisions del Consell Nacionals (Art. 40). La direcció del Partit Socialista és de tipus collegiat (Art. 3/G); el primer secretari és un primus inter pares, però en qui recau tot el pes específic de personalització del partit. Cal remarcar que els dos primers secretaris del partit provenien del Moviment Socialista de Catalunya. A partir del Congrés Extraordinari de 1983,

19. Els dos òrgans de control del partit en l'àmbit nacional són la Comissió Nacional de Confictes (Art. 44) i la Conissió General de Control Financer (Art. 47). La Comissió Nacional de Conflictes és l'encarregada en el si del partit de resoldre els expedients instruïts per faltes dels afliats. Els seus membres són incompatibles amb qualsevol càrrec d'elecció pública, càrtec del partit a nivell federal o nacional, o ésser fưn: cionari del partit. La Comissió General de Control Financer, que és un òrgan que també se situa a nivell de Federació com a control de les Agrupacions, "és l'òrgan encarregat de supervisar l'administracio dels mitjans del partit i controlar que el setu ús estigui adequat a les resolucions dels òrgans competents» (Art. 47).

20. Composició del Consell Nacional (Art. 34 dels Estatuts del 1984). 
s'instituí la figura simbòlica de president del partit, la qual recaigué en el funs aqueli moment primer secretari, Joan Reventós, que fou substituït en el càrrec per Raimon Obiols.

La Comissió Executiva s'estructura en diferents Secretaries, les quals formen el Secretariat (Art. 10) i el Ple de la Comissió Executiva. A partir del IV Congrés (1984), s'instituí el Ple de la Comissió Executiva, que està integrat, a més de pels membres del Secretariat, pels membres elegits pel Congrés. La presència d'aquests membres en el si de l'Executiva, sense responsabilitats de gestió directa, les quals corresponen al Secretariat, cal ba" sar-la en criteris personals, del pes polític de cadascun d'elis en el partit.

\section{RELACIONS INTERNES I EXTERNES}

Per discernir el funcionament de l'estructura interna del Partit Socialista, cal analitzar quin tipus d'articulació i d'enllaços té. L'articulació del Partit Socialista tendeix a estructurar-se a partir d'unes divisions administratives de caràcter territorial, la comarca, el municipi i el barri. L'estructura interna del partit, a més, s'esglaona en forma piramidal.

L'articulació del partit és complexa, rígida i forta. Complexa, ja que les parts de cada nivell formen el tot, i cada part conforma el nivell sta. perior. Cap d'elles no pot funcionar sense l'altra. Rígida i forta, ja que tant els Estatuts del partit com els diferents Reglaments interns en regulen de manera minuciosa la vida interna.

Aquesta minuciositat es tradueix en gatantir la participació tant dels afliats com dels diferents elements organitzatius que el componen a tots els nivells. És, en certa manera, l'intent de mantenir en l'interior del Partit Socialista els principis de la democràcia política, tant per la separació de funcions com per la participació. Aquesta participació es tradueix en el fet que en els diferents nivells estiguin sempre representats els tivells inferiors. Però aquesta democràcia interna és més aparent que teal ja que cal tenir en compte diversos factors que la retallen.

Un primer factor, per mesurar l'articulació, és la incidència del sistema electoral, en aquest cas el proporcional, «l'esctutini de Ilista, funcionant en el marc d'una gran circumscripció, obliga els comitès o les seccions locals del Partit a establir entre si una forta articulació dins de la circums. cripció, per posar-se d'acord sobre la composició de les llistes. Si l'escrutini de Ilista coincideix amb la representació propotcional, l'absència pràctica del panacbage i l'establiment d'un ordre rigorós entre els candidats, 
que determina llur elecció, encara és més gran l'obligació d'articular-se fortament».21

El sistema proporcional comporta dos altres factors que cal tenir presents. Per una banda, la centralització en un òrgan dirigent de la designació dels candidats: «La designació dels membres del Partit candidats a càrtec de representació pública correspondrà al Consell Nacional tenint en compte les propostes dels òrgans de direcció del Partit corresponents a les circumscripcions del seu àmbit territorial, d'acord amb el reglament que aquest elabori» (Art. 49). Per l'altra, el sistema electoral intern del partit. Com afirma Sartori, «sempre que el partit és important, això és, sempre que les carreres polítiques han de passar pel sistema de carrera del partit, aleshores la variable clau... és el sistema electoral intern, $\mathrm{i}$ això és aixú, perquè l'activitat electoral representa, des del punt de vista dels que estan en el poder, l'element central de la seva estructura d'oportunitats. Això implica dues prediccions o previsions: 1) que el comportament de les élites del partit reflectirà una estratègia d'explotació màxima del sistema electoral, 2) que les tàctiques de recompensa de la maximalització del vot es modificatan quan vagi evolucionant el sistema electoral».. ${ }^{22}$ A més, el Partit Socialista aplica la clàusula de l'exclusió a les minories que no obtinguin un percentatge determinat per poder expressar-se com a tal en el si del partit. ${ }^{23}$

Cal distingir dos tipus d'enllaços: el vertical i l'horitzontal. En el Partit Socialista es comprova que el nexe d'unió entre els nivells interns es realitza a través d'enllaços verticals, és a dir, entre organismes subotdinats: d'Agrupació a Federació, de Federació a Consell Nacional o d'Agrupació a Comissió Executiva del partit, o viceversa, del Consell Nacional o de la Comissió Executiva cap a baix. Es veu que el Consell Nacional i, sobretot, la Comissió Executiva són omnipresents en tota l'estructura del partit. «En els partits d'articulació forta els enllaços horitzontals conserven un caràcter excepcional.» ${ }^{24}$

\section{Relacions externes: Relacions amb el PSOE}

Les relacions del Partit Socialista amb el PSOE estan emmarcades sota el signe de l'ambigüitat, com es desprèn de la lectura dels diferents documents i Estatuts, ja que no es pot apreciar de manera clara quin tipus

21. Duverger, M., op. cit., p. 75 .

22. Sattori, G., Partidos y sistemas de partidos, Madrid, Alianza Ed., 1980, p. 136.

23. Sartori, G., op. cit., p. 139.

24. Duverger, $M$, op. cit., p. 79. 
de relació mantenen ambdós partits. Aquesta ambigüitat cal cercar-la, en primer lloc, en l'elaboració del Pacte d'Abril de 1977, pel qual el PSC-C $i$ la FC del PSOE arribaren a un acord electoral com a primer pas vers una futura unitat. En segon lloc, en el Protocol d'Unitat, aprovat pels diferents partits fundadors en llurs respectius Congressos, es palesa que per a la FC del PSOE el nou partit era, en el fons, una Federació més del PSOE, cosa que no era per als altres dos partits, PSC-C i PSC-R, per als quals la nova formació havia d'ésser un partit federat amb el PSOE.

En definitiva, el Protocol d'Unitat que sotgí batreja les dues concepcions dels partits fundadors, primant, per una banda, la independència del partit, però disminuint-la en altres aspectes. Per exemple, en el pla sindical amb el decantament cap a la UGT com a «opció sindical» del partit. No fou fins l'any 1982, en el III Congrés, que es reconegué la UGT com l'únic sindicat socialista i l'obligació dels afliats de militar-hi. També en les relacions internacionals, ja que el partit no pot participar en la Internacional Socialista, representació teservada al PSOE; o, finalment, en la delimitació de la competència del partit en l'àmbit exclusiu de Catalunya i a temes catalans.

Jurídicament, el Partit Socialista és plenament independent del PSOE, per la seva inscripció en el Registre de Partits Polítics, tal $\mathrm{i}$ com ho recorda la sentència de la Junta Electoral Central dictada el 1986, quan afirma que «finalmente, la impugnación de la asignación de espacios al Partit dels Socialistes de Catalunya (PSC.PSOE) carece de fundamento puesto que esta entidad politica figura inscrita en el Registro de Partidos Politicos como distinta e independiente del PSOE; presentó candidaturas propias y obtuvo diputados propios en las elecciones el 28 de octubre de 1982, con independencia del PSOE y, finalmente, en el trámite de alegaciones se aporta acta notarial de constitución del Partido, otorgada el 31 de agosto de 1978, en la que consta que se disolvió y extinguió la Federación Socialista de Cataluña del PSOE, constituyéndose el PSC-PSOE por la fusion de otros partidos politicos y sin vinculación juridica con el PSOE», ${ }^{25}$

En principi, la relació entre ambdós partits és determinada pel Protocol d'Unitat de 1978, que és qui regeix les relacions dels socialistes catalans amb el PSOE, com així ho recorda la Disposició Addicional Primera dels Estatuts del partit estatal: «La articulación orgénica de los partidos federados surgidos de procesos de unidad socialista, se regulará por lo establecido en los respectivos acuerdos de unidad aprobados por el Congreso correspondiente.»

25. Sentència de la Junta Electoral Central de 17 de febrer de 1986, p. 7. 
Els Estatuts del PSOE regulen els partits federats i les Federacions i els donen forma. La regulació estatutària del partit estatal cobreix diferents aspectes, que es poden enumerar en els termes següents. En primer lloc, la denominació del partit: "Cada partido o federación de Nacionalidad o Región determinará su propio nombre que deberá ir necesariamente acompañado de las siglas PSOE» (Art. 15). A tall d'anècdota, cal fer esment que fou Raimon Obiols qui proposà la denominació del nou partit unificat. Recordem que en el IV Congrés del Partit Socialista, el novembre de 1984, hi hagué una moció per eliminar les sigles emmarcades dins del parèntesi, moció que fou retirada a darrera hora i, per tant, no votada.

En segon lloc, l'estructura interna del partit i l'estructura dels òrgans de direcció: «Son brganos del Partido o Federación Nacional o Regional» (Art. 19).

En tercer Iloc, la ratificació dels Estatuts aprovats pel partit federat pel Comitè Federal: «La denominación, organización y estatutos de cada Partido o Federación Regional o de Nacionalidad, tendrán que ser ratifi. cados por el Comité Federal en el plazo máximo de seis meses desde su presentación.." ${ }^{26}$

En quart lloc, en cas de conflicte entre òrgans del partit federat i el partit estatal, aquest pot suspendre'ls: "Cualquier actuación de los órganos de las colectividades que integran el Partido que resultase contraria a lo establecido en estos Estatutos, a las resoluciones del Comité Federal o de la Comisión Ejecutiva Federal, podrá ser suspendida y dejada sin efecto por decision de la Comisión Ejecutiva Federal, remitiéndose la resolución definitiva a la primera reunión que celebra el Comité Federal» (Art. 20). ${ }^{27}$

Recordem el cas de la crisi del II Congrés el 1980, en el qual el PSOE evità la tuptura del PSC no reconeixent el sector que havia abandonat les sessions congressuals. Però, les tensions entre PSOE i PSC es mantenen. Puhle afegeix que «en todos estos conflictos la Ejecutiva se ba impuesto, y con frecuencia Altonso Guerra, en su calidad de presidente

26. Memòria de Gestió del Comitè Federal del PSOE de 1984, p. 36.

27. Caciagli, M., Elecciones y partidos en la transición española, Madrid, CIS, 1986, p. 218: «Las agrupaciones provinciales mantienen autonomía en este y ofros tervenos, aunque las instancias que parecen decisivas, también como canales de enlace con el centro, son las federaciones nacionales o regionales o, cuando existen, los partidos sacio. nates. Se hizo necesatia en el postfranquismo cuando la cuestion de la nacionalidad se revelo como una de las más graves para el nuevo sistema: el PSOE, acusado en et pasado de "ceniralismo" $y$ de "estatismo", se adaptb a las nuevas exigextias, si no por otras razones, aceptando las condiciones imptuestas por algunas formaciones nacionales en el momento de la unificacion.» De Esteban, J.; López Guerra, L., op. cit., p. 174. Bofill, P., «La estructura interna», a Morodo et al., Los partidos políticos en España, Barcelona, Labor, 1979, p. 189. 
de la Comisión Nacional de Listas, ha desempeñado un papel central en estos procesos. A pesar del aumento de la unidad y de la disciplina del partido ad extra, que fueron alcanzadas finalmente, estas luchas internas costaron basta 1979 votos a los socialistas, $y$ a veces ban desmotivado a sus afiliados $y$ a sus simpatizantes». ${ }^{28}$ En aquest sentit, Bofill afirma que «obviamente, la actuación de los órganos de las federaciones es fiscalizada por los órganos superiores del partido, para evitar la desmembración del mismo. La unidad del partido queda asegurada a través de sus órganos máximos de dirección». ${ }^{29}$

El Protocol d'Unitat regula la participació dels membres del partit en el Comitè Federal del PSOE i llur possible elecció en la Comissió Executiva Federal, com ho expliciten diferents articles dels Estatuts del Partit Socialista: «El Partit dels Socialistes de Catalunya (PSC-PSOE) en virtut de la seva sobirania decideix la seva participació als organismes decisoris i representatius comuns amb el PSOE. L'àmbit territorial del partit és Catalunya. La seva actuació fora de Catalunya es regeix per aquests Estatuts» (Art. 2). L'article 4 diu que «amb la finalitat de definir, conjuntament amb els altres socialistes de l'Estat, els elements estratègics coincidents amb la lluita de classes, el partit enviarà els seus delegats al Congrés Federal del PSOE perquè participi en sessions, debats $i$ ressolucions que facin referència a les qüestions comunes de la lluita de classes a nivell estatal. El partit està representat al Comitè Federal. Aquesta representació es designarà en funció d'allò establert als Estatuts i d'acord amb els criteris de proporcionalitat en virtut del nombre de militants. Els membres del partit candidats a la Comissió Executiva Federal seran presentats, o en el seu cas refrendats pel Partit, a través dels propis delegats que siguin presents al Congrés Federal». El primer secretari del Partit Socialista és membre nat del Comitè Federal (Art. 27 PSOE). Els representants del partit en el Comitè Federal són elegits pel Congrés i són membres nats del Consell Nacional (Art. 34), i els membres del partit de la Comissió Executiva Federal poden assistir a les reunions de la Comissió Executiva (Art. 41).

El partit ha de pagat una quota al PSOE estipulada segons el nombre d'afiliats. No s'ha d'oblidar, com així ho estableixen els Estatuts del PSC, que «els militants del Partit que tinguin la seva residència a d'altres nacionalitats o regions d'Espanya sollicitaran l'admissió a la corresponent Agrupació del Partit o Federació del PSOE. Recíprocament, els militants

28. Puhle, H. J., «El PSOE: un partido predominante y heterogéneo», a Linz Montero (eds.), Crisis y cambio: electores y partidos en la España de los años ocbenta, Madrid, CEC, 1986, p. 335.

29. Bofill, P., op. cit., p. 192. 
del PSOE que passin a fixar la seva residència a Catalunya, sollicitaran l'admissió a la corresponent Agrupació del Partit dels Socialistes de Catalunya (PSC-PSOE)» (Art. 8d).

Shabad afirma que uno pocas de las decisiones del gobierno socialista ban producido también tiranteces entre el PSC-PSOE y los líderes socialistas en Madrid. Según Raimon Obiols, Secretario General del PSC-PSOE, el gobierno de González mantiene una "cierta inercia jacobina" respecto al proceso autonómico. Consecuentemente, algunos socialistas catalanes ban sostenido que el "PSC debe recuperar su personalidad especifica, distinta de la del PSOE, y su propia politica en lo que concierne a todo lo que esté relacionado con lo que tenga que bacerse en Cataluña" ${ }^{3} .^{30}$

Si s'ha parlat d'ambiguiitat és perquè el Partit Socialista és jurídicament independent $i$ sobirà; les seves relacions federals amb el PSOE estan regulades, en principi, pel Protocol d'Unitat, però la realitat ens demostra que en molts aspectes el Partit Socialista té unes relacions de federació amb el PSOE, i això comporta dependències, com s'ha vist, contradictòries envers el partit estatal. Obiols afirma que «el PSC ni és un partit federat a un mateix nivell, ni és una Federació del PSOE. En la participació d'un projecte comú d'un programa socialista existeix una telació de dependència amb pèrdua d'una part de la sobirania del Partit». ${ }^{31}$

\section{AFILIACIO}

L'afliació socialista a Catalunya ha anat creixent de manera gradual en el període 1979-1985 fins a situar-se en una xifra de dotze mil afiliats des de 1983. Aquests dotze mil afiliats representen tan sols el 0,28 per cent de taxa d'afiliació a Catalunya sobre el cens electoral. El Partit Socialista no és una excepció, ja que els partits polítics espanyols tenen una de les taxes més baixes d'Europa.

Aquest creixement de l'afiliació ha sofert dues aturades, en 1981 i 1985, a causa de les derrotes electorals sofertes en les eleccions autonòmiques de 1980 i de 1984. Així mateix, l'acceleració en el creixement cal basar-la en la victòria electoral en les legislatives de 1982, on el partit passa de 9.365 afiliats l'octubre de 1982 a 12.631 el juny de 1985 . Aquesta constatació ve a ratificar les propostes sobre la matèria de l'estudiós italià Bar-

30. Shabad, G., "Las elecciones de 1982 y las autonomías», a Linz-Montero (eds.), op. cit., p. 578 .

31. Entrevista personal realitzada a Raimon Obiols els dies 26 d'octubre i 6 de novembre de 1987 . 
tolini, el qual afirma que el nombre d'afiliats augmenta en els anys electorals $\mathrm{i}$ en l'any següent, per després declinar fins a un nou any electoral. 32

L'augment del nombre d'afiliats del Partit Socialista en el període 1980.1985 representa una taxa de creixement del 57,40 per cent $\dot{i}$ el 40 per cent només en el període 1981-1984, la qual cosa representa, sense cap mena de dubtes, l'etapa de consolidació del partit pel que fa a afiliació. Si la comparació es realitza anyalment, l'evolució de l'aftliació segueix l'aftrmació de Bartolini. Als dos creixements de 1979-1980, segueix un decreixement el 1981, que es torna a repetir el 1985, i de nou un creixement elevat en el període 1982-1983, encara que el segueixi un any, 1984, de baixa dins del creixement. El primer període correspon a les victòries electorals a les legislatives $i$ a les municipals; el segon període representa les dues derrotes sofertes pels socialistes en les eleccions autonòmiques, i el tercer període, de nou, té un creixement explicable per les victòties en les legislatives i municipals.

En I'informe de gestió presentat al IV Congrés el 1984 s'analitza la distribució comarcal del creixement. El secretari d'organització afirma que «la distribució territorial del creixement del partit no és homogènia. Per sota de la taxa mitjana d'altes del conjunt del partit, que podríem situar en el 30 per cent anual, se situen un conjunt de comarques que dibuixen un cert mapa d'estancament relatiu del partit: l'Alt Penedès, el Garraf, l'Anoia i Osona al segon cinturó de la província de Barcelona; el Barcelonès Nord a l'entorn del metropolità; el Baix Camp, el Priorat, la Terra Alta i la Ribera a la província de Tarragona i les comarques de muntanya (el Pallars, l'Ait Urgeli, la Cerdanya) a la província de Lleidas. ${ }^{33}$

¿Fins a quin punt aquestes baixes no es deuen més a la passivitat de l'afiliat que a qüestions de "política» del partit? Aquesta pregunta és difícil de contestar. En els informes de gestió, el secretari d'organització atribueix les baixes a la passivitat, menys el 1982, on es pot llegir que «del conjunt de baixes, es pot dir que només un 15 per cent d'aquestes, és a dir, entre 100 i 200 , s'ha produit amb una significació política claxa i específica, afectant aquestes de forma particular les comarques gironines, alguna comarca de la província de Tarragona i alguna Agrupació de la Federació de Barcelona $\mathrm{i}$ el seu cinturó». ${ }^{34}$

La implantació del Partit Socialista cal analitzar-la des de diferents angles. En primer lloc, el PSC està implantat de manera homogènia i forta

32. Bartolini, S., «Gli iscriti ai partiti di massa: Analisi dell'esperienze socialista in Europa (1889-1978)», a Rivista Italiana di Scienza Politica, núm. 2, 1982, pp. 241-278.

33. Informe de Gesti6 de 1984, p. 17.

34. Informe de Gestió de 1982, p. 13. 
en les cinc comarques que tepresenten demogràficament el 80 per cent de la població total de Catalunya, és a dir, el Baix Llobregat, el Barcelonès, el Maresme i el Vallès Oriental i l'Occidental. L'afliació socialista en aquestes cinc comarques el 1979 era de 4.944 membres i el 1985 havia passat a 8.103, que representen el 65,31 per cent i el 64,15 per cent, respectivament, del total. Aquest fet demostra una forta concentració de l'afiliació del partit en unes zones determinades, formant un nucli bàsic i molt homogeni.

En segon Iloc, té una implantació ferma en 17 comarques, on l'afiliació socialista supera la xifra de 100 membres per comarca, tenint en compte que 7 comarques superen els 200 afiliats cadascuna. Cal constatar que la implantació del Partit Socialista cobreix totes les comarques del litoral i algunes de l'interior del Principat.

En tercer lloc, hi ha una implantació feble en 16 comarques, on la penetració del Partit Socialista és menor de 100 afiliats i en alguns casos és purament simbòlica, essent Ia Vall d'Aran i l'AIt Urgeil uns bons exemples en aquest sentit. Totes aquestes comarques se situen a l'interior de Catalunya.

Si s'analitza la implantació en els municipis on el partit té afiliats, es comprova una feblesa estructural. Només en tres comarques el partit té presència en tots els seus municipis (el Baix Ebre, el Barcelonès, el Montsià). En la resta de comarques s'aprecia una manca total d'implantació municipal. El Partit Socialista té presència organitzada en 261 agrupacions, encara que algunes incloguin més d'un municipi en el seu interior i, a l'inrevés, alguns municipis englobin més d'una agrupació. Aquesta xifra representa tan sols el 28 per cent del total de municipis del Principat. En altzes paraules, el Partit Socialista no té cap tipus de presència d'afiliats en quasi 675 municipis.

Observant el nucli bàsic de més implantació i les zones on la implantació és rellevant i les zones on és molt feble, es pot afirmar que el Partit Socialista es caracteritza per una afliació que se situa de manera predominant en les zones més urbanes i més industrials, on existeix una taxa elevada d'immigració. De la mateixa manera, el Partit Socialista no aconsegueix implantar-se en les zones més rurals, sobretot les més deprimides econòmicament, i on existeix una taxa baixa d'immigració, és a dir, en línies generals, l'anomenada Catalunya pobra. 


\section{DIRECCIO I DIRIGENTS}

L'estudi de l'estructura interna de la direcció i dels dirigents del «cercle interior», ${ }^{35}$ en paraules de Duverger, planteja un seguit de qüestions. D'entrada cal desbrossar les dades per cercar els orígens fundacionals dels membres que componen el Consell Nacional en el període 19781984, i cal esmentar que tota l'anàlisi es basa sobre les dades del PSC, sense entrat a considerat els càrrecs dirigents de l'etapa prefundacional. D'altra banda, cal esbrinar si existeix un nucli dirigent estable, redüt i precís, que ens indiqui si realment tenim a la vista el centre de la direcció socialista. El problema, aleshores, és saber quins són realment els membres que tenen un pes decisiu en l'interior del Consell Nacional.

L'altra quiestió que es płanteja, sense cap mena de dubte, és l'anàlisi de la renovació i el recanvi de la direcció, i si es troba un nucli dirigent teduït, estable, precís $i$ homogeni, o, en canvi, cal parlat d'una monocràcia, com ho estudià $i$ definí Schonfeld: «L'oligarquia és una manera de dominació en la qual una petita coalició tendeix a exercir una influència desproporcionada sobre les decisions collectives d'un grup. ${ }^{36}$

L'anàlisi se centra estrictament en "l'òrgan màxim de ditecciós del partit entre Congressos, és a dir, el Consell Nacional, compost pels membres de la Comissió Executiva del partit, pels membres elegits pel Congrés i per les Federacions, que s'anomenaran consellers, i pels membres del partit que formen part del Comitè Federal del PSOE.

Les qüiestions que se'ns plantegen en estudiar les dades són: veure quin pes específic té cada un dels tres partits fundadors en el si del Consell Nacional del partit unificat; i en segon lloc, si aquest pes específic és demostratiu de l'existència d'influències dins del partit per part d'un d'aquells i si existeix una tendència d'equilibri en la tepresentació de les tres parts o, en canvi, existeix una decantació vers un d'ells. Cal recordar que la composició i el nombre de membres en els òrgans de direcció del nou partit foren pactats entre els partits fundadors. Fou a partir del 1980 que es trencà el repartiment dels càrrecs dirigents a partir de les respectives quotes, en vèncer el sector encapçalat per Raimon Obiols, que propugnava la seva eliminació.

D'aquestes quiestions i a la vista de les dades es desprèn que el PSCCongrés manté, en tot el període 1978-1985, un predomini constant en

35. Duverget, M., op. cit, pp. 165-230.

36. Schonfeld, W. B., "La théorie de l'oligarchie de Robert Michels», a Revze Française des Sciences Poltitiques, vol. 30, núm. 4, 1980, p. 858. 
els tres nivells del Consell Nacional, és a dir, la Comissió Executiva, la tepresentació del partit en el Comitè Federal del PSOE i en els consellers. Predomini quantificat en una proporció de 2 a 1 respecte a la Federació Catalana del PSOE i de 8 a 1 respecte al PSC-Reagrupament. En aquest darrer cas, es pot afirmar que la representació del PSC-R és escassa o nulla.

Fins $i$ tot la crisi del partit en el II Congrés el 1980, amb la sortida. de la FC del PSOE de les instancies superiors del partit, sobretot de la Comissió Executiva, no va variar sensiblement la proporcionalitat entre aquesta i el PSC-C.

Cal esmentar, en darrer terme, el creixement progressiu d'un quart segment com és el representat pels membres que no provenen de cap dels tres partits fundadors. Creixement lògic $\mathrm{i}$ explicable per la tenovació de les instàncies superiors amb membres afiliats després de 1978.

Per tant, els quadres procedents del PSC-C tenen un predomini, amb un ferm control, en les instàncies superiors del partit. En canvi, els procedents de la FC del PSOE hì són minoritaris. Això comporta un equilibti inestable entre els dos segments representatius de dues sensibilitats $i$ tradicions diferents. Ja que, quan un d'ells trenca aquest equilibri, en un sentit o en un altre, el partit entra en crisi.

Quina identitat $\mathrm{i}$ quines característiques té el Partit Socialista? Cadascun dels dos segments és representatiu d'un tipus de socialisme, pels seus orígens històtics, $\dot{i}$, en el si del partit, la línia majoritària representa el socialisme societal i la branca minoritària és representativa del socialisme estatal. Són els dos exponents de les «dues cultures» esmentades per Michel Rocard, però també representen les dues tradicions i sensibilitats que s'han anat formant a través del continutm històric. Aquestes dues concepcions del socialisme i la seva representació per part de cadascun dels dos segments ens porten a deduir $i$ a explicar-nos les contradiccions en el si de! socialisme català. Contradiccions, per una part, per l'herència històtica de la concepció del socialisme, i, per l'altra, pel sector de la societat catalana que tepresenta cada segment. Contradiccions que ens explica la presència en el partit de dues tradicions que existeixen, ja no en teoria pel fet de la unitat, però sí en la pràctica i en la demostració de les dades en els diferents quadres.

Fixant-nos en les dades que es desprenen del quadre estadístic, es veu reflectida la preeminència incontestable del PSC-C en totes les instàncies del partit. Comprovem també l'existència dels dos segments, PSC-C i FC del PSOE, un majoritari i l'altre minoritaxi. En tercer lloc, l'escassa o nulla representació del PSC-R. En quart lloc, el creixement del nombre de membres que no pertanyen a un dels tres partits fundadors (NPO), que supera la FC del PSOE i el PSC-C en el nombre de consellers. 
*Papers»: Revista de Sociologia

Pes específic de cada partit fundador en percentatges sobre el nombre total de membres (1978-1984)

\begin{tabular}{|c|c|c|c|}
\hline & $C N$ & $C E$ & $C F$ \\
\hline 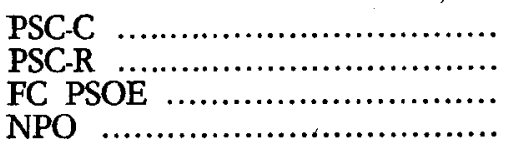 & $\begin{array}{r}31,90 \\
5,48 \\
13,81 \\
48,81\end{array}$ & $\begin{array}{r}53,52 \\
4,22 \\
26,76 \\
15,50\end{array}$ & $\begin{array}{l}46,43 \\
28,57 \\
25,00\end{array}$ \\
\hline & $n=420$ & $\mathrm{n}=71$ & $\mathrm{n}=28$ \\
\hline
\end{tabular}

NoTa: NPO = membres que no pertanyen a un dels tres partits fundadors; $\mathrm{CN}=$ consellers; $\mathrm{CE}=$ Comissio Executiva; $\mathrm{CF}=$ membres del partit en el Comite Federal del PSOE.

Es comprova que el PSC-C és majoritari, la FC del PSOE minoritària i el PSC-R quasi inexistent. Aquest quadre segueix la tònica general marcada pel predomini del PSC-Congrés en totes les instàncies del Consell Nacional. Es pot afirmar que existeixen dues sensibilitats i cultures en el partit $o$, per definir-ho millor, dues tradicions del socialisme, que estan representades pels partits fundadors en el si del partit unificat.

Els tres segments que componen el Consell Nacional representen numèricament el 18,56 per cent per la Comissió Executiva, el 79,25 per cent pels consellers i el 2,19 per cent pels membres del Comitè Federal. La reunió de tots aquests ens permet veure que els nous membres representen el 49,90 per cent de mitjana del total, mentre que els membres estables són el 44,32 per cent $i$ els membres cridats el 5,78 per cent; això totalitza el 50,10 per cent. Es a dir, que existeix un equilibri d'un 50 per cent entre nous membres i membres estables i cridats. Aixd representa una renovació senzilla del 53,77 per cent $\mathrm{i}$ una renovació de l'élite del 49,90 per cent, amb una taxa de renovació explicada pel creixement dels efectius del 27,52 per cent.

Cal tenir en compte en aquestes dades, com en les anteriors, els efectes de la crisi del II Congrés el 1980, ja que els nous membres representen el 65,45 per cent del total, un 25 per cent $i$ un 21 per cent superiors al grup dels nous de 1982 i 1984.

Aquest desajustament explica, en gran mesura, la igualació de les dades en un 50 per cent amb els altres grups, estables $i$ cridats. Aquesta dada de 1980 és la que trenca amb una tendència posterior a l'estabilitat en la renovació $i$ el recanvi dels diferents òrgans del Consell Nacional.

Els càrrecs d'elecció pública en el si del Consell Nacional representen el 48,57 per cent del total en el període de 1978 a 1984, és a dir, quasi la meitat dels membres del Consell Nacional han ocupat algun càrrec d'elec- 
ció pública, mentre n'eren membres, en nombre de 204 sobre 420 membres que han compost el màxim òrgan de direcció del partit entre congressos des de la seva fundació.

Existeix una preeminència de representants del poder local -alcaldes, regidors i diputats provincials- amb un 72,56 per cent, mentre que el grup dels parlamentaris -Congrés de Diputats i Parlament de Catalunya- és només d'un 21,56 per cent.

El nombre de membres amb doble mandat s'incrementa fortament en el si de la Comissió Executiva, essent el 70,42 per cent del total, invertint-se la preeminència vers el grup dels parlamentaris amb un 47,89 per cent.

¿Quina explicació cal donar de les taxes de membres amb doble mandat? En primer lloc, es comprova una acumulació de càrrecs que reforça la tendència oligàrquica en el si del partit. Direcció que és collegiada. En aquesta direcció collegiada és on la doble representació és més elevada, ${ }^{37}$ confirmant el tipus de direcció que el partit posseeix. Es pot afirmar, a la vista de les dades, que existeix una absorció $\mathrm{i}$ interpenetració entre la direcció del partit $i$ els càrrecs electius, fet que encamina vers una forta concentració del poder $i$ un predomini dels notables.

En segon lloc, si ens fixem en la distribució dels membres del Consell Nacional entre els antics partits fundadors, confirmem que el nombre dels procedents de l'ex-PSC-C és majoritari enfront de l'ex-Federació Catalana del PSOE, tant pel que fa al Consell Nacional amb el 37,31 per cent contra el 20,90 per cent, com a la Comissió Executiva amb el 58 per cent enfront del 30 per cent, mentre que el PSC-R és pràcticament inexistent. Els antics membres del PSC-C quasi doblen els efectius de la Federació en els tres casos. Aquestes dades també es confirmen si l'anàlisi es realitza amb els càrrecs electes. Només en el si del Consell Nacional els membres que no provenen de cap dels tres partits fundadors s'apropen a la xifra del PSC-C amb un 36,32 per cent $i$ possiblement, si es manté aquesta tendència, en anys successius el superaran. La visió d'aquestes dades ens referma en la idea de l'existència de les dues cultures i sensibilitats representades pel PSCC i la FC del PSOE, en equilibri inestable en el si del partit unificat.

El nucli bàsic del Partit Socialista, el «cercle interior del cercle interior», si es pot utilitzar aquesta expressió, el componen aquells membres que han participat en tots els Consells Nacionals, quatre en total, en el període que va des de la fundació del partit el 1978 fins al 1984.

Aquest nucli reduit, que sobresurt de l'estudi de les dades del Con-

37. Els càrrecs de designació no han estat comptabilitzats.

7. 
sell Nacional, ${ }^{38}$ està format per 36 membres estables, que representen el 8,57 per cent del total de 420 membres que han format part del maxim òrgan de direcció entre Congressos. Cal tenir en compte que d'aquests 36 membres, 8 ho han estat sempre de la Comissió Executiva.

$\mathrm{El}$ nucli bàsic concentra en el seu si un gran nombre de membres actius en la creació $\mathrm{i}$ fundació del Partit Socialista. Aquests 36 membres representen el nucli dirigent estable del partit. No es pot afirmar que siguin un poder misteriós, fora del control del partit. Tampoc no hi ha cap tipus de demostració que aquest nucli no es transformi en un altre de més teduitt dins de la línia dels dirigents aparents $i$ dels dirigents en l'ombra, com apunta Duverget. ${ }^{39}$ Empíricament, per tant, hi ha constància de l'existència d'aquest nucli mínim, però no es constata que el poder de decisió política passi per aquest. Els seus noms, els seus càrrecs $\mathrm{i}$ el pes específic que tenen dins del partit ens ho pot donar a entendre, però només com a hipòtesi diff́cilment demostrable.

La direcció del Partit Socialista no és de tipus monocràtica. El model de Schonfeld ${ }^{40}$ és aplicable a altres partits, com el PSOE o el PS francès. ${ }^{41}$ No és el cas del PSC, ja que el poder no és ostentat per una sola persona que controla el partit i nomena directament els seus collaboradors, els quals tenen un pes important en el si del partit, com és el cas francès. Com afirma Puhle, "si el PSOE tiene un problema, éste no es el del Leadersbip democrático, sino en el peor de los casos el de extender y consolidar la democracia interna y la participación politica desde abajo. El lider parece asegurado, fuerte $e$ indiscutido, de forma actualmente unica en las democracias europeas. Pero depende esencialmente de una sola persona,

38. Sha comptabilitzat la pertinença al Consell Nacional, sense tenir en compte els períodes temporals. En aquest sentit, en el grup de 36 membres que han estat en tots els Consells Nacionais, a dos els manca un any per cobrir tots els anys del període 1978-1984.

39. Duverger, M., op. cit., p. 176.

40. Vegeu eis dos articles de Schonfeld, W. R., «La stabilité des dirigeants des partis politiques», a R.F.Sc.P., vol. 30, núm. 3, 1980, pp. 477.505, i «La théorie de l'oligarchie de Robert Michels», a R.F.Sc.P., vol. 30, núm. 4, 1980, pp. 946.966.

41. Cayrol, R., «La direction du Parti Socialiste», a R.F.Sc.P., vol. 28, nún. 2, 1978, pp. 201-219: "L'étude du fonctionnement de la direction et du siège central du Parti socialiste est toutefois compliqué par le fait qu'd cette légitimité "démocratique" se superpose une autre source de légitimité: celle qui provient de la confiance accordée par le premier secrétaire. On sait le rốle joué par François Mitterrand à la tête du Parti socialiste depuis 1971. (...) Tout celà ajouté sans doute au tempérament personnel de l'bomme et à ses babitudes en matière - de leadership- explique que, d'une manière pragmatique, non prévue par les statuts, se soit creé une structuration de la direction du parti qui he procède que de lui,» 
que no puede ser reemplazada ni siquiera por sus más estrechos colabo. radores». ${ }^{42}$

Però en cas de crisi en un partit amb un líder monocràtic, els efectes que produeix aquesta són descrits per Schonfeld de la manera següent: «En raison du rôle primordial joué par le leader de sa tendance de l'organisation à s'identifier au leader, la succession se traduit toujours par une crise. Le remplacement d'un monocrate produit toujours un bouleversement important et brutal du personnel de direction, aussi bien que de la stratégie et peut-être du style du parti. Avec un nouveau chef naît une nouvelle organisation. $\gg^{43}$

Un bon exemple d'aquest tipus de crisi es troba en el PSOE i en la figura del seu màxim dirigent, Felipe González. Les dues crisis a les quals em refereixo són les de 1972-1974 i 1979. Ambdues provocaren una crisi interna del partit que va produir un canvi profund d'estratègia i d'estat en el seu si. En canvi, la crisi del II Congrés el 1980 només produeix un desajustament per la retirada d'una de les tendències fundacionals de la direcció del partit, variant l'equilibri intern, però aquesta retirada no trenca el tipus de partit, ni varia substancialment el personal que el componia abans ni després de la crisi.

Es pot parlat de monocràcia en aquells partits en els quals hi ha una figura incontestable $\mathrm{i}$ incontestada, encara que la tendència a la personalització del poder a través dels mitjans de comtnicació porti tots els partits a tenir una figura visible. I un dels problemes bàsics del Partit Socialista és com el votant visualitza la seva imatge."

Cal observar un factor bàsic, com és que la creació del sistema espanyol de partits s'ha establert en un país on la televisió ja havia penetrat, a diferència d'altres democràcies on el fet televisiu és posterior a l'establiment del sistema de partits. Aqquest fet també ha incidit en el tipus de liderat dels partits polítics. En la seva preferència a dirigir-se directament als elec-

42. Puhle, H. J., «El PSOE: un pattido predominante $y$ heterogéneo», a LinzMontero (eds.), Crisis y cambio: electores y partidos en la España de los años ochenta, Madrid, CEC, 1986, p. 343. Caciagli, M., op. cit., p. 220: «Felipe González dispone de un gran poder que le viene de una especie de "carisma situacional"; frectuente en la fase de (re)construcción de los partidos y, en su caso, consagrado por los Congresos de 1979 y por la votación de 1982. Aunque no todo el partido se identifica con él, González es un verdadero recurso para el PSOE. Lo es como imagen bacia el exterior y como "locomotora electoral", lo es cara al interior como punto de encuentro y de equilibrio de diferentes fuerzas e impulsos."

43. Schonfeld, W. R., op. cit., p. 860.

44. Puhle, H. J., op. cit., pp. 342-343. 
tors i a l'opinió pública en general, menystenint, en certa mesura, el paper bàsic anterior dels afiliats. ${ }^{45}$

No bem d'oblidar que la propaganda electoral es dirigeix a la franja d'electors indecisos i que referma la predisposició favorable del mateix electorat. Aquesta propaganda electoral s'ba individualitzat a tot arreu en un líder que simbolitza el partit i les seves idees. Es pot afirmar que els socialistes catalans estan mancats d'aquest lider incontestat i incontestable que els «simbolitzi» audiovisualment, ja que el poder en el Partit Socialista no és de tipus monocràtic i d'adhesió cabdillista, sinó de tipus collegiat i oligàtquic. En altres paraules, existeix un nucli bàsic, estable, reduit $\mathbf{i}$ homogeni de ditigents que no s'ha de cercar entorn dels 36 membres estables únicament, sinó que cal cercar-lo en les taxes de renovació de la Comissió Executiva, que són realment molt baixes, i en la renovació del Consell Nacional que ofereix una mobilitat que és més deguda al desajustament de la crisi congtessual de 1980 que no realment el que demostra l'estabilitat posterior, que se situa entorn al 40 per cent. ${ }^{46}$

\section{CONCLUSIONS}

Les caractetístiques internes del partit es poden situar en la problemàtica dels «partits de masses», examinant l'aplicabilitat dels criteris proposats pel politòleg francès Maurice Duverger. En primer lloc, l'afiliació al partit és directa, amb un mecanisme de cotitzacio individual reglamentat estatutàriament. La seva estructuració es basa en diferents esglaons: local, federació $\mathrm{i}$ nacional. Les relacions entre tots es realitzen verticalment, $\mathrm{i}$ cal una comissió coordinadora, aprovada per la instància superior, perquè es puguin realitzar horitzontalment. En segon lloc, l'articulació del partit és complexa, rígida i forta; és reglamentada de manera molt minuciosa en l'intent de garantir la democràcia interna. Però, d'igual manera que en els partits de masses, existeixen diferents factors que l'atenuen. El primex factor és el sistema electoral proporcional, que prima l'organització nacional (central) sobre les altres. Aquesta organització centralitza, de diversa for-

45. Bartolini, S., op. cit., p. 254.

46. Schonfeld, W. R., op. cit., p. 858: «Instituer une oligarcbie efficace est un processus délicat et difficile qui nécessite un parfait équilibre entre les diverses composantes de l'organisation. Quand un tel équilibre est atteint, les dirigeants ont intêret à éviter toute perturbation. Puisque les changements de personnel sont succeptibles d'introduire un déséquilibre, les oligarchies cherchent à maintenir les taux de rénovation et de remplacement d un seuil minimum.» 
ma, la designació de candidatures. El segon factor és la clàusula de l'ex. clusió de les minories que no obtinguin la quota mínima per esser representades als òrgans de govern. El primer factor centralitza el PSC «territorialment», el segon bo fa "políticament».

La renovació i el recanvi de la direcció i dels dirigents del partit parteix d'un moment inicial, el procés d'unificació, i la repartició dels càrrecs sobre la base d'unes quotes per cada partit fundador. Un dels possibles mo. tius de la crisi del II Congrés el 1980 per part del sector que, posterior. tnent, vencé en aquest Congrés, fou l'intent d'eliminar aquelles quotes, sota els postulats de realitzar realment la unitat i de no mantenir artificialment l'existència de les otganitzacions pre-fundacionals. La crisi del II Congrés motivà, a part de la sortida d'un sector del partit dels òrgans de direcció, una forta renovació interna en el si del Consell Nacional, màxim òrgan de direcció del PSC entre Congressos.

$\mathrm{El}$ tipus de direcció és collegiat. El primer secretari és un primus inter pares, però la tendència a la personalització del poder $\mathrm{i}$ a la visualització d'un líder que simbolitzi el partit $i$ els seus ideals ha portat a una preponderància del primer secretari sobre els altres. En segon lloc, de les dades es desprèn que existeix un nucli estable en el si de la Comissió Executiva, la qual té uns índexs de renovació baixos que ens indiquen que el recanvi ha estat escàs.

Hi ha una forta tendència a la centralització del poder en un nucli dirigent estable, reduit i relativament homogeni. $\mathrm{Cal}$ retenir una dada: en les tres instàncies del Consell Nacional es comprova el predomini de mem. bres que es poden emmarcat dins de la tradició socialista catalana, la qual cosa ens indica la impregnació en aquests nivells d'una de les dues cultures que conformen aquest partit.

L'afiliació al Partit Socialista es concentra bàsicament en cinc comat. ques, que representen el 65 per cent del total del cens d'afiliats del PSC. Aquestes comarques són el Baix Llobregat, el Barcelonès, el Maresme, el Vallès Occidental i l'OrientaI; tenint en compte, a més, que el Barcelonès representa per si mateix el 35 per cent de l'afiliació del partit. Les dades mostren que la implantació, en xifres d'afiliats, del PSC se situa de manera predominant en les zones urbanes $\mathrm{i}$ industrialitzades, amb un grau elevat d'immigració. En canvi, la seva implantació és escassa en les zones rurals, poc industrialitzades, amb una baixa taxa immigratòtia.

Geogràficament l'establiment socialista se situa concèntricament entorn de Barcelona-ciutat, com un nucli bàsic; als municipis que formen la desapareguda Corporació Metropolitana en un segon nivell; i, finalment, a les comarques que envolten la Ciutat Corntal: el Partit Socialista és més urbà que tural. 
La implantació del Partit Socialista en institucions de poder ha conformat unes élites dirigents $\mathrm{i}$, en gran mesura, un tipus de partit. $\mathrm{La}$ victòria electoral del 1982 amb l'arribada dels socialistes al govern de l'Estat, donà lloc a la corresponsabilitat del partit en les tasques de govern amb la participació de dos ministres en el primer govern González. Suposà, també, el transvasament de quadres del partit cap a llocs de responsabilitat de l'Aỏministració central.

El fet més important, però, i que ha marcat més el PSC ha estat, sens dubte, la implantació del partit a nivell municipal. El PSC ha vençut en les tres eleccions municipals celebrades fins al moment, $i$ ha controlat o controla els ajuntaments més importants de Catalunya. El punt clau cal situar-lo en la victòria socialista en les primetes eleccions municipals del 1979 , ja que aquesta victòria local donà pas a la generació conformada políticament els anys seixanta cap a llocs de tesponsabilitat totalment nous per uns homes $\dot{i}$ dones formats, en gran mesura, en la clandestinitat. La gradual municipalització del partit a partir del 1979 s'ha anat eixamplant cada cop més, i és un fet evident avui en dia. Aquesta municipalització del PSC es traspassa també a l'interior del partit en els òrgans de direcció. La classe política formada en els ens locals té una forta representació en el si dels òrgans dirigents del partit.

És a partir d'aquesta municipalització que els grans temes de debat intern $\mathrm{i}$ extern han aflozat. La modernització de la societat, l'autonomia local i el seu apropament al ciutadà o la idea dels Jocs Olímpics de Barcelona, entre d'altres, sorgiren dels líders municipals del PSC. A diferència del PSOE, que es caracteritza més per ésser un partit de govern i de construcció de l'Estat en la línia de la seva tradició, el PSC es caracteritza essencialment per ésser un partit més municipal, més proper al nivell local, dins de la més pura de les tradicions que l'emmarquen. 